\title{
ESTRATÉGIAS EMPRESARIAIS PARA VENCER A CRISE: UM ESTUDO EM EMPRESA DO RAMO IMOBILIÁRIO DE PORTO ALEGRE/RS
}

\author{
BUSINESS STRATEGIES TO CONCERN THE CRISIS: A STUDY IN A PROPERTY MARKET \\ COMPANY IN PORTO ALEGRE/RS
}

\author{
Léia Maria Erlich Ruwer ${ }^{1}$, Hamilton Luis Kleinowski ${ }^{2}, \&$ Tayrone Rocha de Souza ${ }^{3}$ \\ 123 IBGEN - Instituto Brasileiro de Gestão de Negócios, Avenida Praia de Belas, n. 1510, Bairro Praia de Belas, \\ CEP 90150-071, Porto Alegre, RS. \\ 1*1eia.ruwer@gmail.com ${ }^{2}$ hamilton@acad.ftec.com.br ${ }^{3}$ tayrone.souza@meuibgen.com.br
}

ARTIGO INFO.

Recebido em: 02.12.2020

Aprovado em: 08.02.2021

Disponibilizado em: 05.03.2021

Palavras-chave:

Estratégias; Mercado Imobiliário; Administração; Crise.

\section{KEYWORDS:}

Strategies; Real estate market; Administration; Crisis.

*Autor Correspondente: Ruwer, L. M. E.

\section{RESUMO}

O presente estudo aborda o tema Administração Estratégica e se propõe a estudar as estratégias empresariais em períodos de crise no ramo imobiliário. Busca-se responder: quais as estratégias empresariais os gestores de imobiliárias adotam em tempos de crise; e, para tanto, o objetivo propõe analisar as estratégias empresarias do ramo durante este período, por meio do estudo de caso de uma imobiliária de grande porte que atua com imóveis de alto padrão, situada em Porto Alegre/RS. Para viabilizar este objetivo, inicialmente constituiu-se o referencial teórico abordando os principais conceitos acerca do tema estratégia (conceptualização, administração e posicionamento estratégico, estratégias de crescimento, competitividade e empresariais na prática; e o delineamento do cenário da crise no período de 2014 a 2017). Como proposta metodológica, o estudo utilizou-se de pesquisa exploratória com abrangência de dados qualitativos. A técnica de coleta de dados utilizada foi entrevista semiestruturada, realizando-se análise de conteúdo e amostra não probabilística. Após a análise dos dados, foi possível observar que as respostas se demonstraram unânimes no que diz respeito às estratégias utilizadas na organização, o que permitiu correlacionar com o referencial teórico abordado, produzindo as conclusões do estudo e demonstrando, principalmente, o direcionamento das estratégias adotadas pela empresa objeto do estudo.

\section{ABSTRACT}

This study addresses the topic of Strategic Management and proposes to study business strategies in times of crisis in the real estate industry. It seeks to answer: what business strategies do real estate managers adopt in times of crisis; Thus, the objective proposes to analyze the business strategies of the branch during this period, through the case study of a large real estate company that works with high standard properties, located in Porto Alegre /RS. To make this objective feasible, the theoretical framework was initially approached, addressing the main concepts about strategy (conceptualization, administration and strategic positioning, growth, competitiveness and business strategies in practice, and the delineation of the crisis scenario in the period from 2014 to 2017). As a methodological proposal, the study used exploratory research with a range of qualitative data. The data collection technique used was a semi-structured interview, with content analysis and a non-sample probabilistic. After analyzing the data, it was possible to observe that the responses were unanimous with regard to the rules used in the organization, which forced them to correlate with the theoretical framework addressed, producing as a study professional and demonstrating, mainly, the direction of strategies adopted by the company object of the study. 


\section{INTRODUÇÃO}

A crise político-econômica que afeta indivíduos, organizações, mercados e estados/nações traz consigo desafios prementes para os gestores contemporâneos. Autores como Barbosa Filho (2017, p. 10) ao abordar a crise (2014-2017) especificam que a mesma resulta de "(...) uma combinação de choques de oferta e demanda, resultado de erros de política econômica. Esses choques produziram uma redução da capacidade de crescimento da economia brasileira e risco de insolvência das finanças públicas". E, como reflexo, estatísticas como o Estudo Demografia das Empresas e Estatísticas de Empreendedorismo (IBGE, 2017) apontam que o Brasil, pelo $4^{\circ}$ ano seguido, fecha mais empresas do que abre.

Neste cenário, é cada vez mais importante que as organizações e seus gestores busquem compreender profundamente e determinar qual é o seu foco de sua atuação; quais consumidores pretendem atender; como se dá sua partição na indústria e qual a estratégia adequada para obter o melhor desempenho no segmento de atuação escolhido. Para tanto, como aponta Porter (2004), a análise e entendimento das forças competitivas proporciona obter algum tipo de vantagem nos mercados altamente competitivos, pelo estabelecimento de uma estratégia para se destacar. Partindo disso, a meta da estratégia competitiva para uma empresa é encontrar um posicionamento no setor onde consiga melhor se defender ou mesmo influenciar em seu próprio benefício.

No ramo imobiliário, exemplo de setor fortemente marcado pela competição, o entendimento dessas forças competitivas se torna cada vez mais exigência aos gestores e profissionais envolvidos; para o enfrentamento das demandas contemporâneas - se fazendo essencial em momentos de crise. Afinal, este é um setor expressivo da economia brasileira - e que sofreu uma queda relevante em vendas no país: em torno de 35\% em 2014 (Lewgoy, 2015).

Essa importância do setor também é destacada pelos dados os levantados pelo Banco de Compensações Internacionais (BID) em 2016; que apontam que a valorização imobiliária no Brasil foi de $121 \%$ após o período pós-crise de 2008. Entre 2008 e 2011, a valorização anual ficou acima dos $20 \%$ (G1, 2016). E, a apontando dados da Associação Brasileira das Entidades de Crédito Imobiliário e Poupança (ABECIP), houve um incremento de $42 \%$ no volume de financiamentos para construção e compra de imóveis em 2011 se comparado com o ano anterior, somando R \$ 79,9 bilhões. Foram ainda financiadas 493 mil unidades, $17 \%$ maior que o ano anterior. Já o valor dos imóveis subiu 26\%. Em 2012, houve mais um incremento nos financiamentos, totalizando R \$ 82,8 bilhões, alta de 3,6\% sobre 2011. Em 2013, os números bateram recorde, atingindo $\mathrm{R} \$ 109,2$ bilhões, $32 \%$ a mais do que no ano anterior $(\mathrm{G} 1,2016)$.

Machado (2013) destaca que o mercado imobiliário esteve em alta em 2012 e 2013, sendo que no período de 2012 o Feirão da Caixa vendeu mais de 14 milhões de reais, superando $13 \%$ nas vendas de 2011. Para 2013, as projeções também eram boas, contudo, com os rumores acerca da "bolha comercial", isso se alterou. Mas mesmo assim, ainda segundo o mesmo autor, na época muitas pessoas não acreditavam que poderia acontecer no Brasil o que havia acontecido nos Estados Unidos em 2009; por contas das agências de crédito serem bastante rigorosas na liberação do financiamento, e ainda por exigir uma entrada de $20 \%$ do valor do imóvel, o que favorece uma compra mais consciente.

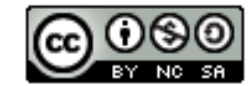



empresa do ramo imobiliário de Porto Alegre/RS. Brazilian Journal of Production Engineering, 7(1), 41-57.

No período 2016 a 2017 chama a atenção o fato de imobiliárias tradicionais fechando as portas, como destacado por Hollanda (2017), devido às dificuldades e por conta da retração dos negócios provocada pela crise econômica.

Em se tratando do cenário local e regional, contemplado pelo presente trabalho; na cidade de Porto Alegre/RS, também houve uma grande queda nas vendas de imóveis. Segundo Lewgoy (2015) foram negociadas 194 unidades em janeiro de 2015; e, se comparados aos números do mês anterior, isso representou uma queda de $71,60 \%$, quando foram vendidas 683 unidades. E, se comparados ao ano anterior registra-se uma queda de $27,34 \%$.

A partir destas informações constrói-se o presente trabalho; que é um estudo de caso e aborda as estratégias utilizadas pelos administradores de uma empresa do ramo imobiliário, para continuar no mercado dentro dos anos em que o Brasil se encontrou em crise (2014-2017). Delimitando-se a região do estudo do setor, para a cidade de Porto Alegre, Estado do Rio Grande do Sul; contemplando uma escolha por conveniência de pesquisa - em função das oportunidades de acesso dos pesquisadores aos sujeitos de pesquisa.

Assim, fica compreendido que, entre 2014 a 2017, segundo os analistas vivencia-se o mercado imobiliário em baixa, e uma situação de crise para o referido setor, que, para fins desse trabalho envolvem: baixas vendas de imóveis, piora significativa na concessão de crédito imobiliário; aliado ao desemprego do país, resultando o fechamento de muitas imobiliárias. Diante do exposto emerge a seguinte questão de pesquisa: Quais são as estratégias empresariais que os gestores do ramo imobiliário adotam em tempos de crise?

E, para responder a essa questão de pesquisa, apresenta-se como objetivo geral: analisar as estratégias empresariais utilizadas durante determinado período dessa ocorrência - a crise - em uma imobiliária de grande porte e foco em alto padrão, situada em Porto Alegre/RS. Tendo como objetivos específicos: a) pesquisar e apresentar os fundamentos teóricos acerca do tema Estratégias Empresariais e Competitividade; b) pesquisar e identificar a percepção dos gestores do ramo imobiliário sobre a crise que atingiu o setor e ações estratégicas empresariais tomadas para o enfrentamento de tal situação; e, c) analisar essas estratégias à luz do referencial teórico apresentando.

Este estudo se justifica pois, a partir da análise das estratégias empresariais utilizadas pelas empresas que se mantiveram competitivas durante e após a crise, pode-se obter subsídios para apoiar outras empresas que enfrentam problemas semelhantes. No ambiente acadêmico o presente conteúdo contribui ao acrescentar dados aos estudos aplicados ao ramo imobiliário, destarte que esta área possui lacunas de produção em termos de estratégia.

\section{REFERENCIAL TEÓRICO}

\subsection{Estratégia: Conceitualização}

Estratégia é uma palavra que possui origem milenar, e, segundo pesquisa de Mainardes et al. (2011) teve seu significado alterado e adequado a novos contextos ao longo do tempo. Da mesma forma, Chiavenato e Sapiro (2009) destacam que estratégia não é um conceito recente, exemplificando que os homens das cavernas já a utilizavam em suas atividades, quando se propunham a pescar, caçar e lutar para conseguir sobreviver. De acordo com esses autores, o 

empresa do ramo imobiliário de Porto Alegre/RS. Brazilian Journal of Production Engineering, 7(1), 41-57.

termo estratégia provém do grego "strátegos" que, inicialmente referia-se a uma posição do general no comando de um exército e depois foi denominada como "a arte do general", expressando a aplicação das competências desse oficial na realização de sua função, em outras palavras: sua arte militar.

Já na época de Alexandre, o Grande (330 a.C), a estratégia representou os esforços empreendidos para fazer frente ao inimigo. Nas guerras helênicas, a estratégia viabilizou inúmeras conquistas e vitórias militares, mesmo com poucos recursos contra o oponente. A estratégia também se fez presente na época dos faraós, quando os arquitetos egípcios desenvolvias os desenhos das pirâmides e as imagens dos faraós e buscando escolher um local adequado para o monumento e mapear os recursos necessários para a sua elaboração (Chiavenato \& Sapiro, 2009).

Mais atualmente, a complexidade da palavra estratégia impede que ela seja definida de forma simples, mas os inúmeros autores convergem para abordar suas principais dimensões, apontando, à exemplo de Kluyver e Pearce II (2007, p. 2), que a mesma diz respeito a "posicionar uma organização para a obtenção de vantagem competitiva. [...] Seu objetivo principal é criar valor acionistas e outros stakeholders ao proporcionar valor para o cliente." Entretanto, independente da definição utilizada, converge-se para o apontamento de Barney e Hesterly (2011), de que a sobrevivência e a prosperidade de uma organização em um mercado estão diretamente relacionadas à escolha e adoção de uma boa estratégia.

\subsection{Administração Estratégica}

Para Wright et al. (2007) a administração estratégica vai muito além de escalar os objetivos que os membros da organização deverão seguir e posteriormente, explicar e dar o direcionamento para se atingir esses objetivos. A administração estratégica depende também de inúmeras considerações e variáveis como: administração das oportunidades e ameaças do ambiente externo e a análise pela administração dos pontos fortes e fracos da empresa.

Para compreender melhor a administração estratégica, Wright et al. (2007) apresentam que palavra estratégia entende-se aos planos da alta administração, podendo-se classificar em três pontos de vantagens que são: o desenvolvimento da estratégia, a colocação da estratégia em prática e o controle da estratégia; e, em outras palavras: pode-se alterar a estratégia caso seja necessário para assegurar que os objetivos sejam atingidos. Segundo os autores, a administração estratégica é rica e ampla, abrangendo, além dos três pontos citados anteriormente, os processos iniciais de uma organização que determinam a missão e os objetivos no contexto de seus ambientes internos e externos.

Desta forma, a administração estratégica pode ser entendida através de uma série de formas e passos em que a alta administração deve proceder atividades, como: a) averiguar as oportunidades e ameaças ou limitações que se encontram no ambiente externo; b) averiguar os pontos fortes e fracos da empresa; c) estipular a missão e os objetivos; c) montar estratégias em todos os níveis da empresa, e que permitam a organização combinar os pontos fortes e fracos com as oportunidades e ameaças do ambiente; d) implementar as estratégias; e, d) conduzir atividades de controle estratégico para assegurar que estão indo conforme os objetivos montados e que atinjam as metas estipuladas. Todas estas atividades são altamente inter- 

empresa do ramo imobiliário de Porto Alegre/RS. Brazilian Journal of Production Engineering, 7(1), 41-57.

relacionadas, pois quaisquer mudanças que sejam feitas poderão comprometer os demais estágios dos processos (Wright et al., 2007).

Barney e Hesterly (2007) destacam que a estratégia se estabelece como um teoria da forma de conseguir vantagens competitivas, visto que uma boa estratégia é aquela que verdadeiramente gera vantagens. Contudo, sabe-se que embora não seja fácil descobrir se a empresa está seguindo a melhor estratégia é possível reduzir a probabilidade de possíveis erros de execução. Frente a isso, chama-se a atenção para a necessidade de escolher uma estratégia de forma cuidadosa e sistemática e acompanhar o processo de administração estratégica - enquanto conjunto sequencial de análises e escolhas, que podem aumentar as chances de que uma organização obter vantagem competitiva.

Já Oliveira (2013) conceitua que a administração estratégica consolida um conjunto de princípios, normas e funções de forma estruturada, sistêmica e intuitiva, com potencial de alavancar o processo de planejamento futuro da empresa como um todo. Contempla ainda, segundo o autor, a organização e a direção dos recursos empresariais de forma otimizada com a realidade, com a maximização das relações interpessoais e com a interação das mudanças dos ambientes externos - que são os não controláveis, com os ambientes internos - que são os controláveis da empresa. Desta forma, esse conceito proporciona a sustentação básica para o desenvolvimento e implementação da administração estratégica nas empresas; e assim, quando o nível de competitividade é mais elevado no ambiente que a empresa se encontra, a administração estratégica é bem mais exercitada pelos gestores, levando-os a serem mais criativos.

Ansoff e McDonnell (1993) destacam que a atividade de administração estratégica envolve a definição das metas e objetivos para a coordenação e o aperfeiçoamento de um combo de relações entre a empresa e o ambiente, tanto externo quanto interno. Dessa forma se possibilita perseguir objetivos e metas, tornando-as compatíveis com a realidade que a empresa se encontra no momento frente ao mercado, permitindo continuar sensível as exigências do ambiente.

Ainda, segundo Ansoff e McDonnell (1993, p. 289): “Um dos produtos finais da administração estratégica é um potencial de cumprimento futuro dos objetivos da empresa”, em uma empresa isto contempla: recursos (recursos humanos, materiais, financeiro e de informação), produtos finais (serviços e/ou bens desenvolvidos) de rentabilidade futura validada e um conjunto de normas de comportamento social que possibilitam a empresa continuar a alcançar suas metas e objetivos traçados. Além do potencial futuro citado acima, os autores citam uma estrutura e uma dinâmica interna, na qual são aptas de preservar a sensibilidade das mudanças que ocorrem no mercado, ou seja, ambiente externo.

\subsection{Estratégias de Crescimento}

As estratégias de crescimento, de acordo com Ansoff e McDonnell (1993) são aquelas que se baseiam em um negócio já existente e no aumento de vendas de produtos e ou na investigação e novos mercados e novos produtos para esse mercado. Assim, uma empresa deve sempre buscar novos mercados e produtos para que aumente seu mix de oferta, pensando na intenção de crescer. Esse processo se torna cada vez mais necessário nas organizações para que se mantenha em uma boa posição frente a um mercado tão competitivo nos tempos atuais. Uma 
Citação (APA): Ruwer,1L.M. E., Kleinowski, H. L., \& Souza, T. R. de. (2021). Estratégias empresariais para vencer a crise: um estudo em empresa do ramo imobiliário de Porto Alegre/RS. Brazilian Journal of Production Engineering, 7(1), 41-57.

forma de identificar essas oportunidades de crescimento, é utilizando a Matriz de Ansoff ou Matriz Produto/Mercado, que possui duas dimensões: produtos (ou serviços) e mercados. Sobre essas duas dimensões, quatro estratégias podem ser formadas, com o objetivo de ajudar na expansão da organização, sendo elas (Kotler \& Armstrong, 1995):

a) Penetração de mercado: os gestores devem maximizar as principais marcas da empresa para alcançar uma maior penetração no mercado, aumentando assim as vendas para os clientes existentes, sem alterar os seus produtos. Apenas utilizando técnicas tradicionais de promoção, preço, atendimento e pós-venda.

b) Desenvolvimento de mercado: verificar, ampliar e conquistar novos mercados para os seus produtos. Explorar os mercados, procurar e atrair novos consumidores, conquistar clientes de marcas concorrentes, mudar faixas etárias de clientes, a fim de estimular novos clientes a comprar os produtos existentes. Devem se usar armas como propaganda, praça e novamente não se deve alterar produto.

c) Desenvolvimento de produto: criar e oferecer novos produtos ou produtos alterados para os mercados já existentes. Necessitam que reinvente os produtos (novos formatos, estilos, tamanhos, cores), ou criar produtos novos na empresa, podendo ser até mesmo de outro segmento, para que possa aumentar o volume de venda para os clientes atuais.

d) Diversificação: essa é a dimensão contempla abrir novos negócios com novos mercados. Pode ser uma grande chance que a empresa tem em conseguir identificar algum mercado necessitado. Contudo, a empresa que se diversificar demais passa a trabalhar com indústrias pouco conhecidas, tendem a perder mercado e sucumbir, por isso seu risco é alto. Desta forma, a empresa cria novos produtos para novos mercados.

\subsection{Estratégia Competitiva}

Segundo Porter (2004) a concepção de uma estratégia competitiva é a busca de uma posição competitiva favorável no mercado onde atua. Direciona em estabelecer uma posição lucrativa e sustentável contra as forças que indicam a concorrência. Estratégia competitiva envolve associar uma organização ao seu ambiente; e, sendo assim, a sua definição se baseia em duas questões fundamentais: a atratividade da empresa e a posição competitiva dentro dela. Para ter respostas mais clara a essas questões, se torna essencial: a) verificar se a empresa é atrativa na rentabilidade a longo prazo; e também, levantar os pontos determinantes dessa atratividade; $b$ ) verificar os pontos determinantes da posição competitiva, que podem ser diferentes, dependendo a empresa. A combinação dessas questões vai definir a escolha da estratégia competitiva a ser adotada; e, desta forma, o desempenho da organização. E, apesar de que seu ambiente relevante seja muito vasto, englobando tanto forças econômicas como sociais, o maior aspecto do seu ambiente são as outras empresas que ela compete.

Nesta perspectiva, Porter (2004) aponta que o estágio da concorrência depende de cinco forças competitivas básicas, que são: a) entrada de novos concorrentes, b) ameaça de produtos ou serviços substitutos; c) poder de negociação dos compradores; d) poder de negociação dos fornecedores; e, e) rivalidade entre os atuais concorrentes. Para o autor, todas essas forças competitivas em conjunto definem a intensidade da concorrência na indústria, empresas e serviços. Após serem levantadas as informações das forças competitivas, a empresa está preparada a identificar seus pontos fortes e fracos em relação ao mercado. Assim, a estratégia competitiva efetiva se atribui uma ação de defensiva ou ofensiva, de maneira a criar uma função 

empresa do ramo imobiliário de Porto Alegre/RS. Brazilian Journal of Production Engineering, 7(1), 41-57.

defensável contra as cinco forças. De forma abrangente, percebe-se uma série de abordagens possíveis: posicionamento da empresa, influenciar o equilíbrio de forças e explorar e antecipar mudanças nas forças (Porter, 2004).

Para Siqueira, et al. (2012) o modelo da posição competitiva é, por vezes, nomeado de modelo de posicionamento, tendo em vista que ao selecionar uma das estratégias genéricas indicadas, a empresa estará indicando uma posição em relação aos seus concorrentes. Quando é feita a análise das cinco forças e também a análise de sua cadeia de valor, o gestor da empresa estará preparado para definir sua escolha. Siqueira et al. (2012) citam ainda que são dois os principais fatores apontados por Porter para uma empresa se destacar ainda mais frente à sua concorrência e que determinam sua vantagem competitiva: baixo custo e diferenciação. Esses fatores estão diretamente associados com o potencial de uma empresa em lidar com as cinco forças; e, se o fizer com mais competência que os concorrentes, poderá ter uma vantagem competitiva alavancada.

São três os tipos de estratégias genéricas (Siqueira et al., 2012):

a) Liderança de custo: estratégia utilizada pelo fabricante ou fornecedor de menor custo, para que possa ter condição de gerenciar os preços. Caso um concorrente queira praticar esta estratégia com maior custo, ele sofrerá com os concorrentes de menor custo. A liderança de custo pode ter ganhos superiores dos concorrentes mesmo quando a empresa não queira reduzir seu preço de venda.

b) Diferenciação: estratégia de conseguir uma particularidade em relação ao seu concorrente e que seja valorizada pelo cliente. Essa característica diferenciada pode estar encontrada nos produtos/serviços. A diferenciação, quando apresenta uma vantagem competitiva, pode trazer ganhos importantes como impor valores superiores devido à sua vantagem sobre os demais concorrentes. Não é aconselhável tentar a liderança de custo e ao mesmo tempo, diferenciação, pois é difícil manter custos baixos quando quer tentar ser diferenciado no mercado.

c) Focalização: estratégia na qual a organização escolhe a seleção de segmentos-alvo, podendo optar em liderança de custo como de diferenciação. São normalmente casos de volumes baixos, quando as maiores organizações preferem não atender, por questões de produção baixa, logística, suprimentos etc. Os produtos de alvo específico são normalmente a compradores com necessidades incomuns.

Siqueira et al., (2012), complementa ainda que todas as estratégias genéricas têm a revisão da vantagem competitiva, pois os concorrentes buscam a todo custo observar as possibilidades que permitem tal vantagem concorrencial e tendem a fazer igual ou buscar soluções mais inteligentes.

\subsection{Estratégias Empresariais na Prática}

Segundo Thompson e Strickland III (2003), a estratégia empresarial reside do conjunto de mudanças competitivas e abordagens comerciais que os gerentes desempenham para atingir o melhor funcionamento da empresa. A estratégia está a todo momento sendo planejada e usada pelos gerentes e gestores das empresas, que a utilizam para lutar e manter sua posição no mercado, promover satisfação dos clientes, atingir os objetivos de desempenho e sem perder a qualidade do produto ou serviço que a empresa está fornecendo. Os gestores projetam estratégias conforme a mudança de mercado vai ocorrendo, em outras palavras, planejando uma 

empresa do ramo imobiliário de Porto Alegre/RS. Brazilian Journal of Production Engineering, 7(1), 41-57.

forma de não ser deixado para trás pelas empresas concorrentes. Sem a estratégia, um gerente não tem uma direção previamente considerável para seguir, fica sem rumo e sem ação (Thompson \& Strickland III, 2003).

Para Bethlem (2009), o plano estratégico é definido junto a empresa no começo do período de estruturação, de forma hierárquica; demandando aos demais membros da organização os objetivos e metas que desejam que a empresa alcance, ou induzindo com que os membros adotem a ideia. Ainda, para o autor, o que deve ser realizado no início do plano e em períodos de tempos diversos, é buscar respostas para as seguintes situações: o que a empresa quer ser? $\mathrm{O}$ que ela quer fazer? Como ela quer estar? E onde vai querer estar em um determinado momento do futuro? A estratégia estabelecida inicialmente deverá ser transformada da ideia para a ação efetiva. O controle dessas estratégias dará feedbacks sobre a atuação na empresa, podendo gerar demanda de correções na implantação e revisões nas estratégias já estabelecidas.

\subsection{A Crise: Cenário 2014-2017}

A economia brasileira vivencia uma recessão desde o segundo trimestre de 2014, como aponta o "Comitê de Datação do Ciclo Econômico" (CODACE-FGV), que entre 2014 e 2016, o PIB (Produto interno bruto) per capita brasileiro, caiu em torno de 9\%, destacando que daí cria-se uma forte pressão para uma reintegração da economia brasileira (Barbosa Filho, 2017).

Segundo Barbosa Filho (2017) a situação atual de recessão, se dá através de um conjunto de resultados de choques da oferta e da demanda. Esses diversos choques atingiram a economia brasileira, realizadas por falhas de políticas econômicas ocasionadas, principalmente, no período em que foram adotadas as políticas que integraram a "Nova Matriz Econômica" (NME), e incorporadas no Brasil em meados de 2011/2012. Ainda para o autor, essas políticas são grandes intervenções governamentais na economia, no qual se planejou uma política fiscal com dirigismo na elevação de gastos, intervenções em preços, investimento e concessão de subsídios e a política monetária com a diminuição da taxa de juros. A política monetária aumenta a taxa de juros quando a inflação está alta e diminui a taxa Selic em situações de desaceleração inflacionária.

Adiante, em 2012, houve aceleração na taxa de inflação, e uma das políticas adotadas pela NME foi a diminuição a taxa básica de juros da economia. Essa mudança na política monetária fez com que a taxa de inflação acelerasse (e continuasse em nível elevado) e diminuiu a credibilidade do Banco Central (BACEN), elevando o custo de combate à inflação. Balassiano (2018, p.1), em seu estudo sobre a Recessão Brasileira (2014-2016), aponta que “(...) a última recessão do Brasil foi do segundo trimestre de 2014 até o quarto trimestre de 2016”. Quanto ao crescimento real do PIB, em 2014 houve crescimento real ligeiro, de $0,5 \%$, enquanto tanto em 2015 quanto em 2016 houve contração 3,5\%. Vale frisar que a última vez em que o país apresentou dois anos seguidos de crescimento real negativo do PIB foi em 1930 e 1921, logo após a Crise de 29. O ano de 2017 foi o primeiro ano pós-recessão, com uma taxa real de crescimento de $1,0 \%$.

Em 2019, o cenário vigente no desenrolar do presente estudo, é o apresentado pelos em seu estudo de Leal (2019): de juros altos, desemprego, baixo crescimento do PIB e uma situação em que se verifica cada vez mais que o país se encontra estagnado economicamente deste e o 

empresa do ramo imobiliário de Porto Alegre/RS. Brazilian Journal of Production Engineering, 7(1), 41-57.

ano 2014, tendo a população como principal prejudicado neste ciclo. Nos aspectos relativos ao mercado, o mesmo se encontra em recessão, com queda da produção de bens e serviços e, por consequência, do poder de consumo.

\section{PROCEDIMENTOS METODOLÓGICOS}

A presente pesquisa utiliza a abordagem exploratória, que segundo Silva e Menezes (2001), objetiva promover maior aproximação com o problema, tornando a situação mais límpida ou permitindo elaborar hipóteses. A pesquisa é qualitativa e realizada por meio de estudo de caso, que abrange um estudo mais aprofundado e exaustivo de um ou mais objetos permitindo o seu amplo e detalhado conhecimento (Silva \& Menezes, 2001). Por conveniência de pesquisa, e por proporcionar possiblidades de responder à pergunta de pesquisa, definiu-se como objeto do estudo de caso uma imobiliária de grande porte de imóveis de alto padrão, situada em Porto Alegre/RS.

Como ferramenta de pesquisa, utilizou-se de uma entrevista semiestruturada, que permite ao entrevistador utilizar perguntas abertas, com a opção de ampliar o questionamento caso necessário, porém com embasamento em questões pontuais pré-estabelecidas (Silva \& Menezes, 2001). A amostra é não probabilística intencional, que diz respeito a um grupo de pessoas ou população que o pesquisador considera como "bons julgadores" e que participaram respondendo os problemas da pesquisa (Silva \& Menezes, 2001). Deste modo, a população é composta por gestores de imobiliária; e os sujeitos da pesquisa serão os gestores da imobiliária da unidade em estudo de caso, por serem os profissionais indicados para apresentar os posicionamentos de gestão adotados e atender aos objetivos da presente pesquisa.

A Análise de Dados contempla a análise de conteúdo, que, de acordo com Bardin (2006) visa identificar a essência das informações transmitidas através de entrevistas, imagens, vídeos, documentos e até mesmo músicas. A análise de conteúdo trabalha com dados qualitativos, concebidos através de comunicações auditivas, visuais e textuais. Esses dados serão posteriormente comparados com o Referencial Teórico, originando as conclusões do presente estudo.

\section{APRESENTAÇÃO E ANÁLISE DE RESULTADOS}

\subsection{Cenário da Pesquisa}

A imobiliária objeto do presente estudo foi fundada em 2010 por quatro sócios que já atuavam no ramo imobiliário e decidiram começar um negócio próprio. Atualmente, um dos sócios desligou-se da participação acionária da empresa, vendendo seu percentual de participação aos demais sócios.

A sede da empresa está localiza em Porto Alegre/RS, e conta com unidades no bairro Três Figueiras, Zona Norte (com três unidades no mesmo prédio) e mais uma unidade no bairro Cristal, Zona Sul da Capital. Conta, atualmente, conta com 50 funcionários (com vínculo em Carteira de Trabalho e Previdência Social - CTPS) e mais de 500 agentes/corretores autônomos.

A imobiliária foi uma das pioneiras do mercado imobiliário a investir em marketing digital; sendo por isso reconhecida com o Top Inovação de Marketing ADVB/RS no ano de 2012. Recentemente, fez uma parceria com uma startup que trabalha com demandas de locação, 

empresa do ramo imobiliário de Porto Alegre/RS. Brazilian Journal of Production Engineering, 7(1), 41-57.

complementando as atividades da imobiliária, visto que a mesma não atuava neste segmento dentro de sua estrutura. Por meio dessa parceria, são utilizadas as dependências da empresa e assessoria do RH, marketing e TI para o desenvolvimento do trabalho; e, em troca, a imobiliária recebe parte do faturamento da startup.

O foco de atuação da empresa, até então, consistia nos imóveis de lançamento (imóveis na planta ou em construção); entretanto, com a mudança na demanda, passou a focar também em imóveis prontos.

\subsection{Dados da Pesquisa}

A entrevista teve como sujeitos quatro sócios-fundadores da empresa e a gerente administrativa, que responde pela da área financeira e gestão de pessoas, desde a fundação da mesma. Para manter o sigilo da fonte e diferenciar os sócios, os mesmos serão citados pelas letras: A, B, C e

D e a gerente administrativa (GA). Todas as entrevistas foram gravadas e seguidas de anotações, com base no formulário semiestruturado construído para esta pesquisa, sendo de igual conteúdo para todos os entrevistados. O contato foi agendados pelo WhatsApp e procedeu-se as entrevistas durante o horário de expediente da empresa, na sala de reunião da sede no bairro Três Figueiras, Porto Alegre/RS.

\subsubsection{Sobre a estratégia: conceitualização}

Os elementos iniciais do questionário buscaram definir o que os entrevistados compreendem por estratégia; e, dentro disso, destacaram-se as falas de GA de que “(...) a nossa trilha, (...) seria a missão e visão, onde quer chegar, não vai adiantar nada, porque vai te perder”. Enquanto para o entrevistado A, a palavra estratégia significa o caminho que se traça no mapa de onde se está até onde se almeja chegar; ou, em outras palavras, a rota. O respondente fez uma analogia com o APP WASE e a mudança de rota; afirmando que "(...) em função das variáveis do mercado, deve-se mudar a estratégia adotada". Também para o sócio entrevistado B, estratégia indica saber onde se quer chegar; enquanto que o sócio entrevistado $\mathrm{C}$, complementa as afirmativas anteriores, destacando o importante papel de “(...) antecipar e depois planejar".

Por essas respostas dos sujeitos, destacaram-se elementos como trilha, a missão, a visão, o caminho, a rota, onde se quer chegar, planejar; entre outros apontamentos. Isso demonstra que a ideia que os mesmos fazem da estratégia está relacionada ao futuro; ou seja: à construção de algo. Portanto, esta ideia está de acordo com os apontamentos de autores Mainardes et al. (2011) que apresenta a estratégia como a definição dos caminhos da organização; e também de Kluyver e Pearce II (2007, p. 2), que apontam que a estratégia trata-se de posicionar uma organização para a obtenção de vantagem competitiva.

\subsubsection{Sobre Administração Estratégica}

Neste ponto, os entrevistados responderam sobre como ocorre a determinação, a implementação e o controle das estratégias - e divergiram um em suas respostas.

A GA apontou em sua fala que “(...) o controle era com os diretores, e não tinha essa noção das outras estratégicas a não ser do que envolvia o financeiro da empresa”. Já para os sujeitos B e

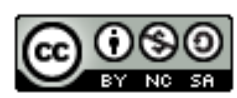



empresa do ramo imobiliário de Porto Alegre/RS. Brazilian Journal of Production Engineering, 7(1), 41-57.

A, o controle era feito nas próprias reuniões semanais da diretoria. Para o sujeito C, esse controle "(...) é a reunião semanal com a gerente financeira".

Assim, evidencia-se que, quanto ao processo de Administração Estratégica, alguns aspectos importantes foram deixados de lado, uma vez que entrevistados demonstraram não manter controles do processo da estratégia em si, realizada no dia a dia. Isso se faz necessário, e, como apontam autores como Wright et al. (2007), a vantagem competitiva provém de um ciclo completo que envolve o desenvolvimento da estratégia, a aplicação dessa estratégia em pratica e controle da estratégia. Sendo que esse controle envolve assegurar que as definições realizadas estão indo conforme os objetivos pretendidos, de forma que proporcionem que as metas estipuladas sejam atendidas.

\subsubsection{Sobre Estratégias de Crescimento}

Dentro deste tema, considerando que o mercado está cada vez mais competitivo, os sujeitos da pesquisa responderam sobre o foco das estratégias para as áreas de marketing, tecnologia, finanças e parcerias realizadas pela empresa no período estudado.

A GA destacou inicialmente as Estratégias de Marketing, com o foco na captação de leads; melhorias na tecnologia e CRM da empresa, site, sistema de chat do online. Apontou ainda as Estratégias Financeiras para aquele momento: não criar novos gastos, renegociação de todos os contratos, trocar fornecedores por mais baratos. A entrevistada pontuou que ainda as Estratégias de Parcerias, como a fixada com uma empresa de vendas de fracionamento de lotes de resort. Para o entrevistado A, destacam-se como Estratégias de Marketing, que a empresa "(...) buscou novas ferramentas e estratégias online para baratear o custo do cliente"; além disso, focou em tecnologia, com “(...) investimento em CRM para tirar o máximo de cada cliente adquirido”. O sujeito também destacou como Estratégia Financeira a "(...) montagem de um orçamento base zero e controle do orçado vs. realizado com uma periocidade mensal”; e a Estratégia de Parcerias realizada “(...) com empresas com imóveis prontos, e parcerias com novos clientes proprietários de imóveis e não incorporadoras”.

Para o entrevistado B, como Estratégia de Marketing destacou-se o enfoque em adwords e o mesmo apontou que "(...) só começamos a investir no que nos dava leads" (...) "então antes se investia campanha disso, campanha daquilo, camiseta, feira, paramos"(...) "porque cada investimento que fazíamos em marketing tínhamos que saber o que é que nos de receita, por isso que usamos bastante internet porque dava para mensurar"; para tecnologia “(...) no nosso sistema próprio (CRM) para que não dependesse de nenhum investidor; para financeiro “(...) redução de custos, reduzir os parcelamentos e encurtar as receitas e ter uma cobrança maior dos inadimplentes”; e sobre parcerias “(...) poucos incorporadores que sabíamos que eram sólidos”.

Para o entrevistado C, a Estratégia de Marketing teve como foco a geração de leads digital e o envio de $e$-books para criar credibilidade com os clientes “(...) o RDStation, tem toda base de clientes que recebe e-mail da empresa, começou a enviar $e$-book para ensinar a comprar com segurança, explica como financiar, explica como deixar seu imóvel bonito, e entre outros"; para tecnologia o entrevistado não soube informar e complementou que o outro sócio poderia esclarecer; enquanto que para as Estratégias Financeiras o mesmo apontou que "(...) "foi a redução de despesa, esse é o foco, tempo inteiro"; e, por fim as Estratégias de Parcerias, do que 

empresa do ramo imobiliário de Porto Alegre/RS. Brazilian Journal of Production Engineering, 7(1), 41-57.

destacou que “(...) foi feito a Credipronto, que é uma linha de crédito e mais recentemente a parceria com a startup de alugueis".

Com as respostas apresentadas percebe-se que existiu, na unidade de estudo, uma busca constante por formas de se manter e destacar no mercado. Com o mercado imobiliário cada vez mais competitivo, cada inovação ou diferencial que a empresa realiza sobre seus concorrentes já proporciona a aquisição de um espaço maior no mercado. Isso se relaciona com o que Katz (2017) aponta quando diz que uma empresa deve sempre buscar novos mercados e produtos com intuito crescer de forma constante. Também para Barney e Hesterly (2007) uma boa estratégia estabelecida é aquela que consegue vantagens competitivas sobre seus adversários.

\subsubsection{Sobre Estratégia Competitiva}

Numa demonstração de como a empresa enxerga a vantagem competitiva sobre os concorrentes e qual o diferencial buscado pela mesma durante o período foco desse estudo, os entrevistados destacaram os seguintes apontamentos:

Para a GA a vantagem competitiva da empresa contemplou “(...) o marketing, nosso posicionamento, pois conseguiu ser referência no mercado, a nossa captação é muito boa, tínhamos corretores muito bons que conseguiam fechar a venda". Além disso, segundo a entrevistada, a empresa buscou fazer diferente dos demais concorrentes: “(...) o controle, não só a venda, e sim olhar as despesas, para não se transformar num elefante branco. Não adianta só querer vender e não olhar para dentro, esse ponto de equilíbrio de captar vendas e fazer boa gestão dentro". Já para entrevistado A, a principal vantagem competitiva se constituiu na “(...) qualificação de mão de obra"; e, como seu diferencial no tempo de crise, ele cita "(...) que foi mudar rapidamente o foco do produto vendido" - referindo-se à mudança dos imóveis de lançamento para imóveis prontos. Enquanto que o entrevistado B destacou que vantagem competitiva da empresa era a “(...) tecnologia, pois tinham uma captação de clientes muito acima do mercado, tudo pelo investimento e pela tecnologia, também tem uma loja bacana e legal" e sobre que a empresa fez de diferente ele cita que foi o marketing, mas não traz mais detalhes sobre isso. E, finalmente, para o entrevistado $\mathrm{C}$, a vantagem competitiva da empresa era "(...) o maior banco de imóveis" e adiciona "(...) nossos treinamentos para corretor e a organização da empresa, nossos processos fazemos funcionar" e sobre seu diferencial durante a crise foi “(...) focar no mercado secundário, só nós fizemos isso. Essa foi a grande mudança, hoje o mercado de imóveis usados representa um torno de $90 \%$ das vendas”.

De acordo com estas respostas, fica ratificado o que aponta Porter (2004), quando destaca que a vantagem competitiva direciona em estabelecer uma posição lucrativa e sustentável contra as forças que indicam a concorrência. E também faz frente à afirmação de Siqueira et al. (2012) que conecta perfeitamente com uma das estratégias genéricas, a diferenciação, pois é estratégia de conseguir uma particularidade em relação ao seu concorrente, com isto apresenta uma vantagem competitiva.

\subsubsection{Sobre Posicionamento Estratégico}

Sobre a posição estratégica da empresa, questionou-se a missão e objetivos da empresa durante e após a crise, e buscou-se elementos para identificar se os mesmos foram colocados em prática

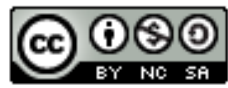



empresa do ramo imobiliário de Porto Alegre/RS. Brazilian Journal of Production Engineering, 7(1), 41-57.

desta forma, ou com alterações. Os entrevistados apresentaram algumas respostas que divergiram entre si:

A GA relatou que “(...) sim, a empresa já possuía missões e objetivos.” E, quando questionada sobre mudanças, a mesma apontou: “(...) do objetivo e missão raiz, eu não sei se mudou ou não, mas o que a gente faz é a cada 2 anos botamos uma campanha: corretor de verdade, corretor do futuro e entre outros". Ao ser solicitada para falar mais sobre as campanhas, apontou que: “(...) daí realizamos todo um engajamento para isto, não necessariamente a missão e objetivo geral, mas eles colocam para esta campanha, para atrair mais corretores, pois muitos foram embora nesta crise e viraram Uber". A entrevistada relatou ainda acreditar que essas campanhas voltadas ao corretor, são tipo objetivos do momento, e com isto a empresa vai criando campanhas para conseguir algo ou alguma coisa, conforme a sua necessidade que está passando. O entrevistado A, informa que a empresa tinha missões e objetivos, mas ele saiu durante a crise da empresa, e enquanto estava lá não houve alterações. O entrevistado B, diz que “(...) as missões e objetivos da empresa ainda são os mesmos"; entretanto, ao ser perguntado sobre se houve alguma alteração durante ou após a crise e ele diz que “(...) tinha que mudar um pouco, depois que começou a crise começamos mudar um pouco a maneira de falar com o corretor".

Já para o entrevistado C, a empresa possuía missão, visão valores e objetivos antes da crise; e, após indagado sobre se houve alguma alteração, a sua fala aponta que “(...) não foi alterado e não foi posto em pratica, pois estas são coisas que já discutimos, nossas missões e conceitos e filosofias se perde com o tempo, deveríamos refazer, para confirmar ou modificar, mas deveria ser refeito, mas nunca foi”.

Estes dados demonstram que os sujeitos tem conhecimento da importância dos elementos analisados, o que confere com o que aponta Oliveira (2014) quando cita que a missão da empresa é a definição da razão central do planejamento estratégico, entretanto, na elaboração inicial da empresa, como dito pelo diretor $\mathrm{C}$ não foi posto em pratica e precisar ser refeito. $\mathrm{E}$ isso não segue adequadamente aos apontamentos dos autores da área de estratégia, que promovem o entendimento como Kuazaqui (2016) de que o planejamento estratégico envolve a forma do método gerencial que autoriza indicar a direção que a organização deverá acompanhar. Ocorreram muitas mudanças no mercado com a crise e a empresa ainda possui os mesmos objetivos, criar campanha e tratar bem os corretores não são passivos de novos objetivos, como diretor C expressa - é necessário refazer, pois se perdeu com o tempo.

\subsubsection{Sobre Estratégias Empresariais na Prática}

Neste ponto, as estratégias empresariais que foram utilizadas no momento da crise foram questionadas aos entrevistados.

A GA destacou que “(...) a estratégia foi virar para o mercado avulso”, em outras palavras, mudaram seu foco de imóveis de lançamentos para imóveis já utilizados. Já o entrevistado A, cita que “(...) são as principais: a mudança de foco dos lançamentos pro mercado secundário, buscar atender um mercado que ainda mantinha um movimento razoável, diferente dos lançamentos que este estancou” e a outra que cita como principal é "(...) ter uma eficiência melhor nos custos, cortar aquilo que não está trazendo valor a empresa”. Para o sócio entrevistado $\mathrm{B}$, “ “...) a estratégia em tempos de crise tanto para pessoa jurídica quanto para 

empresa do ramo imobiliário de Porto Alegre/RS. Brazilian Journal of Production Engineering, 7(1), 41-57.

pessoa física, é cortar despesas e ter caixa, não pagar juros, porque em crise o dinheiro fica mais caro". Enquanto o entrevistado C, cita que "(...) foi tratar o corretor como nosso maior cliente (...) com isso é tratar os caras bem, dar suporte jurídico, pegar as negativas do negócio, é ter o advogado, é ter o fotografo e dar ferramentas para que consiga desempenhar suas atividades".

Por essas respostas dos sujeitos da pesquisa, destacaram-se apontamentos que demonstram a compatibilidade da percepção dos gestores com a ideia de Thompson e Strickland III (2003), quando apontam os gestores das empresas projetam estratégias conforme a mudança de mercado está ocorrendo, eles planejam uma forma de não ser deixado para trás pelos concorrentes e quando os gestores engajam o time para trabalharem juntos, consolidando o rumo de longo prazo da empresa.

\subsubsection{A Crise: Cenário 2014-2017}

Finalizando a entrevista, os sujeitos foram convidados a dar sua versão da crise e apontar fatos que vivenciaram nesse momento.

A GA comentou que “(...) 2014 foi um ano muito bom pra empresa, na verdade a crise ou bolha chegou depois, em 2015 começa uma queda nas vendas e se manteve em 2016 e se estabilizou em 2017 e 2018, porém não se estabilizou como era em 2014”. A entrevistada complementa uma demora para a empresa ser atingida pela crise e conclui que o motivo das vendas terem diminuído é em razão as construtoras não terem fabricado lançamentos, que são imóveis na planta, ou seja, empreendimentos. E comenta “(...) muitas imobiliárias fecharam, pois seu foco eram em lançamentos e não mudaram a chave para os imóveis avulsos". Para o entrevistado A, “(...) foi uma crise bem complexa, foi diferente da crise de 2008. (...) A crise foi potencializada por anos e anos de gastos excessivos do governo e um desarranjo de conta pública, que combinou em ajustes fiscais e impactou forte a economia". O sujeito destaca ainda o não crescimento do PIB per capta e complementa que “(...) teve uma retração do cliente na compra de imóveis por conta da insegurança se realmente poderia pagar, se conseguiria se manter no emprego, se aumentaria sua renda, afinal o financiamento normalmente é de 30 anos”. Enquanto o entrevistado B destacou que “(...) começamos a sentir diferença no modelo de compra de imóveis por parte dos clientes no final de 2014. O cliente antes ia no plantão de vendas, depois parou, com isto tivemos que trazer clientes para plantão, com ligações e $e$-mails". E, por fim, o entrevistado C aponta que, “(...) no início de 2014 o mercado ainda estava aquecido, e muitas imobiliárias acabaram surgindo com um modelo estratégico focado em produto financeiro e não em produto imobiliário.” E complementa que “(...) de 2012 a 2014 os clientes estavam comprando com uma promessa de ganha na venda do imóvel, os clientes compravam para vender e não para morar".

Pelo relato dos entrevistados fica em tela o panorama por que passaram os mesmos e a unidade em estudo, num período em que o mercado não estava aquecido e o consumo se manteve baixo, fazendo com que não se verificasse uma renovação no ciclo econômico: queda de vendas, cenário político, mudança no perfil de cliente e cenário imobiliário. Essas informações, são compatíveis com o quadro apresentado por Barbosa Filho (2017) e Balassiano (2018) que aponta que em 2015 e 2016 houve contração no crescimento do PIB, com anos seguidos de crescimento real negativo.

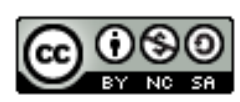



empresa do ramo imobiliário de Porto Alegre/RS. Brazilian Journal of Production Engineering, 7(1), 41-57.

\section{CONCLUSÃO}

O estudo aqui desenvolvido teve por objetivo identificar as estratégias empresariais que devem ser adotadas em tempos de crise no ramo imobiliário. Para atingir esse propósito foram definidos e atendidos os seguintes objetivos específicos: a) Pesquisar e apresentar as referências teóricas acerca do tema estratégias empresariais - concretizado por meio do levantamento de dados e pesquisas bibliográficas que deram origem ao capítulo de referencial teórico, base para as análises referentes ao presente estudo; b) Identificar a percepção dos gestores imobiliários sobre a crise que atingiu o setor - concretizado por meio do estudo de caso de uma imobiliária de grande porte e imóveis de alto padrão, situada em Porto Alegre/RS; e, c) Identificar, descrever ações e providências frente a identificação da crise; e também medidas para o enfrentamento de tal situação e analisar as estratégias utilizadas à luz dos principais teóricos da área - concretizado por meio da apresentação e análise dos resultados, trazendo as respostas dos sujeitos entrevistados e sua referida análise à luz das teorias estudadas.

Desta forma, foi identificada a percepção dos gestores de um empreendimento do ramo imobiliário, buscando respostas sobre a questão de pesquisa: Quais são as estratégias empresariais que os gestores do ramo imobiliário adotam em tempos de crise? Compreendendo que em momentos como os de crise (2014-2017), a empresa deveria adotar o desenvolvimento de uma estratégia e seu devido controle. A presente pesquisa buscou averiguar se a empresa considerou em suas preocupações as oportunidades e ameaças ou limitações que se encontram no ambiente externo; os pontos fortes e fracos da empresa; a devida estipulação da missão e dos objetivos - de forma a montar estratégias em todos os níveis da empresa para permitir que a empresa pudesse combinar esses pontos fortes e fracos com as oportunidades e ameaças do ambiente, e assim definir sua estratégia competitiva.

Assim, as principais percepções oportunizadas pela pesquisa, afirmam que os gestores demoraram para sentir a crise na empresa, entretanto, quando perceberam, tiveram que tomar a decisões rápidas, e a principal escolha destacada foi a estratégia de focalização (Siqueira et al., 2012), na qual a organização escolhe segmentos-alvo específicos para atenção. Assim, a estratégia da empresa que era focada em imóveis de lançamentos (imóveis na planta) foi alterada para imóveis prontos (usados). Além disso, foram destacadas outras estratégias adotadas pela imobiliária, que compuseram o quadro resumo apresentado a seguir (Quadro 1):

Quadro 1. Estratégias Empresariais Adotadas pela Imobiliária em Estudo ESTRATÉGIAS EMPRESARIAIS ADOTADAS PELA IMOBILIÁRIA EM ESTUDO

\begin{tabular}{|c|c|}
\hline ESTRATÉGIA & DETALHAMENTO \\
\hline MARKETING & $\begin{array}{c}\text { Investimentos em tecnologia e sistema de atendimento ao cliente; marketing digital; } \\
\text { campanhas de leads; } \text { adwords; } \text { - } \text {-mail marketing; anúncios patrocinados; estreitamento } \\
\text { do relacionamento com corretores. }\end{array}$ \\
\hline FINANÇAS & $\begin{array}{c}\text { Política austera de custos, com renegociação de contratos; negociação com fornecedores; } \\
\text { substituição de fornecedores; troca de materiais equivalentes em função do valor. }\end{array}$ \\
\hline COMPETITIVA & Foco em imóveis prontos, enquanto seus concorrentes ainda insistiam em imóveis em \\
lançamentos.
\end{tabular}

Fonte: Autores, 2019.

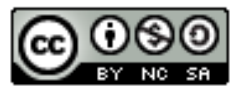


Citação (APA): Ruwer,1L.M. E., Kleinowski, H. L., \& Souza, T. R. de. (2021). Estratégias empresariais para vencer a crise: um estudo em empresa do ramo imobiliário de Porto Alegre/RS. Brazilian Journal of Production Engineering, 7(1), 41-57.

Como limitação da pesquisa destaca-se a negativa de participação de um dos sócios da empresa, que era o responsável pelo marketing e tecnologia da empresa - e que poderia agregar mais informações e detalhas às descrições dos demais entrevistados.

Como observação e sugestão de melhoria para a imobiliária em estudo, proveniente das entrevistas, recomenda-se para que os sócios se reúnam e revisem a missão, visão, valores e objetivos da empresa, pois em vista da divergência nas respostas sobre este tema, além de observar-se o desconhecimento da real virtude do que a empresa deseja obter e sobre onde ela quer realmente ir. E também não há nenhuma informação acerca disso no site, redes sociais ou mesmo exposta dentro da empresa sobre esse norteador estratégico.

Como possibilidades de futuras pesquisas, sugere-se investigar as estratégias de outras imobiliárias do mesmo local, em Porto Alegre/RS, ou até mesmo de outras localizações, como cidades ou estados e também pesquisar imobiliárias de outros portes.

\section{REFERÊNCIAS}

Ansoff, H. I., \& MCDonnell, E. J. (1993). Implantando a Administração Estratégica. Tradução de Antonio Zoratto Sanvicente, Guilherme Ary Plonky. 2. ed. São Paulo: Atlas.

Balassiano, M. G. (2018). Recessão Brasileira (2014-2016): Uma Análise por Meio do Método do Controle Sintético do PIB, PIB per capita, Taxa de Investimento e Taxa de Desemprego. In: Anais do XLVI Encontro Nacional de Economia. ANPEC-Associação Nacional dos Centros de PósGraduação em Economia [Brazilian Association of Graduate Programs in Economics].

Barbosa Filho, F. de H. (2017). A crise econômica de 2014/2017. Estudos Avançados, 31(89), 5160. https://dx.doi.org/10.1590/s0103-40142017.31890006.

Bardin, L. (2006). Análise de conteúdo (L. de A. Rego \& A. Pinheiro, Trads.). Lisboa: Edições 70, (Obra original publicada em 1977).

Barney, J. B., \& Hesterly, W. S. (2007). Administração Estratégica e Vantagem Competitiva. Tradução de Monica Rosemberg. São Paulo: Pearson Prentice.

Bethlem, Agricola. (2009). Estratégia Empresarial: Conceitos, processo e administração estratégica. 6. ed. São Paulo: Atlas.

Carvalho, T. D. (2018). O que é crise econômica? Politize, 12 dez. 2018. Recuperado de https://www.politize.com.br/crise-economica-o-que-e/

Chiavenato, I., \& Sapiro A. (2009). Planejamento Estratégico. 2. ed. Rio de Janeiro: Elsevier.

Hollanda, M. (2017). Corretores de imóveis partem para negócio próprio com a crise no setor imobiliário. Natal: Agora RN. Recuperado de http://agorarn.com.br/economia/corretores-deimoveis-partem-para-negocio-proprio-com-a-crise-no-setor-imobiliario/

Recuperado de http://www.clicrbs.com.br/especial/rs/editorial-imoveis/19,0,3962929,Foxterconquista-o-premio-Top-Inovacao-do-Top-de-Marketing-ADVB-RS-2012.html/

Katz, P. (2019). Estratégias de crescimento para uma empresa no ramo da construção civil. 2017. Recuperado de https://www.univates.br/bdu/bitstream/10737/1764/1/2017PedroKatz.pdf

Kluyver, C. A. de, \& John A. P. (2007). Estratégia: uma visão executiva. Tradução de Monica Rosemberg. 2. ed. São Paulo: Pearson Prentice Hall.

Kotler P., \& Armstrong, G. (1995). Princípios de Marketing. Rio de Janeiro: LTC Editora.

Kuazaqui, E. (2016). Planejamento estratégico. São Paulo: Cengage Learning.

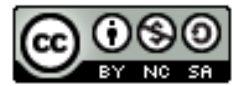


Citação (APA): Ruwer,1L.M. E., Kleinowski, H. L., \& Souza, T. R. de. (2021). Estratégias empresariais para vencer a crise: um estudo em empresa do ramo imobiliário de Porto Alegre/RS. Brazilian Journal of Production Engineering, 7(1), 41-57.

Leal, I. de L. S. (2019). Crise Econômica do Brasil contemporâneo. Recuperado de https://wwww.easychair.org/publications/preprint_download/pR8Q

Lewgoy, J. (2015). Mercado Imobiliário passa por período de ajuste. Recuperado de https://www.jornaldocomercio.com/site/noticia.php?codn=190455

Machado, G. (2013). Análise do Mercado Imobiliário 2013. Recuperado de http://guilhermemachado.com/analise-do-mercado-imobiliario-2013/

Mainardes, E. W., Ferreira, J., \& Raposo, M. (2011). Conceitos de Estratégia e Gestão Estratégica: Qual é o nível de conhecimento adquirido pelos estudantes de gestão? Facef. p. 278-295. Recuperado de http://periodicos.unifacef.com.br/index.php/facefpesquisa/article/viewFile/296/284

Mintzberg, H., Lampel, J. B., Quinn, J. B., \& Ghoshal, S. (2006). O processo da estratégia: conceitos, contextos e casos selecionados. Tradução de Luciana de Oliveira da Rocha. 4. ed. Porto Alegre: Bookman.

Oliveira, D. de P. R. de. (2013). Administração Estratégica na Prática: A competitividade para administrar o futuro das empresas. 8. ed. São Paulo: Atlas.

Oliveira, D. de P. R. de. (2014). Estratégia empresarial \& vantagem competitiva: como estabelecer, implementar e avaliar. 9. ed. São Paulo: Atlas.

$O$ auge e a queda do mercado imobiliário em uma década. G1. (2016). Recuperado de http://g1.globo.com/especial-publicitario/zap/imoveis/noticia/2016/04/o-auge-e-queda-domercado-imobiliario-em-uma-decada.html

O efeito da crise no setor imobiliário: queda de 17\% nos preços em três anos. (2018). São Paulo: Gazeta do Povo. Recuperado de https://www.gazetadopovo.com.br/economia/livre-iniciativa/oefeito-da-crise-no-setor-imobiliario-queda-de-17-nos-precos-em-tres-anos-

ddvih4euw0yvitxxbr4z53kiz/

Porter, M. E. (2004). Estratégia Competitiva: Técnicas para análise de indústrias e da concorrência. Tradução de Elizabeth Maria de Pinho Braga. 2. ed. Rio de Janeiro: Elsevier.

Silva, E. L., \& Menezes, E. M. (2001). Metodologia da Pesquisa e Elaboração de Dissertação. 3. ed. Florianópolis: UFSC.

Silveira, D. (2017). Por dois anos seguidos, Brasil fecha mais empresas do que abre, aponta IBGE. Rio de Janeiro: G1. Recuperado de https://g1.globo.com/economia/noticia/por-dois-anos-seguidosbrasil-fecha-mais-empresas-do-que-abre-aponta-ibge.ghtml

Siqueira, J. P. L. et al. (2012). Estratégia para corporações e empresas: Teorias atuais e aplicações. São Paulo: Cengage Learning.

Thompson, A. A., \& Strickland, A. J. (2003). Planejamento Estratégico: Elaboração, implementação e execução. Tradução de Francisco Roque Monteiro Leite. 1. ed. São Paulo: Pioneira Thomson Learning.

Wright, P., Kroll, M. J., \& Parnell, J. (2007). Administração Estratégica. Tradução de Celso A. Rimoli, Lenita R. Esteves. 1. ed. São Paulo: Atlas. 